\title{
DTC hybrid by different techniques of observation with Artificial Neuronal Network (ANN) for induction machine drives
}

\author{
Dris Ahmed ${ }^{1}$, Bendjebbar Mokhtar ${ }^{2}$, Belaidi Aek ${ }^{3}$ \\ 1,3 Electrical Engineering Department, ENP University, Algeria \\ ${ }^{2}$ Electrical Engineering Department, UST.Oran, Algeria
}

\begin{tabular}{l}
\hline Article Info \\
\hline Article history: \\
Received Aug 8, 2018 \\
Revised Nov 19, 2018 \\
Accepted Mar 1, 2019 \\
\hline
\end{tabular}

\section{Keywords:}

DTC-ANN

Induction Machine drives

KUBOTA

MRAS Observers

Total Harmonic Distortion

(THD)

\begin{abstract}
In this article, we present the construction of observers of rotor flux and mechanical speed needed for robust control of the induction machine. Two observers will be developed for comparison. The first is based on the techniques MRAS and the second is observer of KUBOTA, with the enhanced DTC-ANN (by artificial intelligence), "sensorless DTC-ANN". The validity of the proposed methods is confirmed by the simulation results. Through this comparative study we examine each observer in terms of characteristics that distinguish him from the other through these estimated value and error of estimation (flux and the speed of rotation) on the one hand, and on the other hand we study a property of great importance in the control and the response and robustness of the observer for very low speeds. In my work I concentrate this on the observer of KUBOTA because I noticed that during my research in the previous research and research there is very little and no detail even in terms of mathematical model in addition to the form of comparative study between him and the observer of MRAS in terms of the principle of control, accuracy, sensitivity and special response to low speeds and error In observation.The THD (Total Harmonic Distortion) of stator current, torque ripple and stator flux ripple are determined and compared with conventional DTC control scheme using Matlab/Simulink environment.
\end{abstract}

Copyright (C2019Institute of Advanced Engineering and Science. All rights reserved.

\section{Corresponding Author:}

Dris Ahmed,

Electrical Engineering Department, ENP University,

Bp 1523 El M'NOUER, Oran, Algeria.

Email: drisahmed82@yahoo.com

\section{INTRODUCTION}

Getting high performance with an asynchronous machine, requires complex control including requiring reliable information from process control, this information can reach the sensors, they dedicated the weakest link in the chain, so it tries to fill their functions by calculation algorithms reconstructing the machine states, such tools are the name of estimators and observer for reasons of cost or technological reasons, it is sometimes too restrictive measure some quantities of the system. However these quantities may represent important information for control or monitoring [1]. It is necessary to reconstruct the evolution of these variables that are not directly from the sensors. We must therefore carry out an indirect sensor. For this, the estimators are used or as appropriate, observers [2].

The DTC control methods of asynchronous machines appeared in the second half of the 1980s as competitive with conventional methods, based on pulse width modulation (PWM) power supply and on a splitting of flux and motor torque by magnetic field orientation, Indeed, the DTC command from external 
references, such as torque and flux, does not search, as in conventional commands (vector or scalar) the voltages to be applied to the machine, but search "the best "state of switching of the inverter to meet the requirements of the user [3].In order to reduce ripples of the electromagnetic torque and the stator flux in both motors and to ensure a relatively higher switching frequency, the aforementioned facts, are exploited to develop a new control scheme based on the algorithm [3,4].The presentation of the synthesis of our observer of sliding type is very easy. The question of sensitivity of the control system, to the variations of the parameters of the machine $[3,5]$.The comparative analysis among these four speed estimation methods shows that reactive power MRAS with NFC (Neuro Fuzzy controlled) as adaptation mechanism shows reduced speed estimation error and actual speed error at steady state operating conditions when the drive is subjected to low speed operation $[3,6]$.

Major disadvantage of DTC is the ripple on the couple and the flux and to remedy this last problem one improves the control DTC by several techniques among these methods are modification the tables of selection, the artificial intelligences which is interested in this article and the flux is estimated by the KUBOTA observer. In this work, our main objective is to exploit artificial intelligence tools namely: artificial neural networks on the DTC control and on the observer, where we use the observer ofKUBOTA to estimate the speed and the flux and take as a model to compare it to technique MRAS and we express the estimation error then THD of stator current is evaluated.

\section{DTC CONTROL}

Depenbrock and I. Takahashiproposed DTC control of the asynchronous machine in the mid-1980s, it has become increasingly popular. The DTC control makes it possible to calculate the control quantities that are the stator flux and the electromagnetic torque from the only quantities related to the stator and this without the intervention of mechanical sensors [7].

The principle of control is to maintain the stator flux in a range. The block diagram of the DTC control is shown in Figure 1.

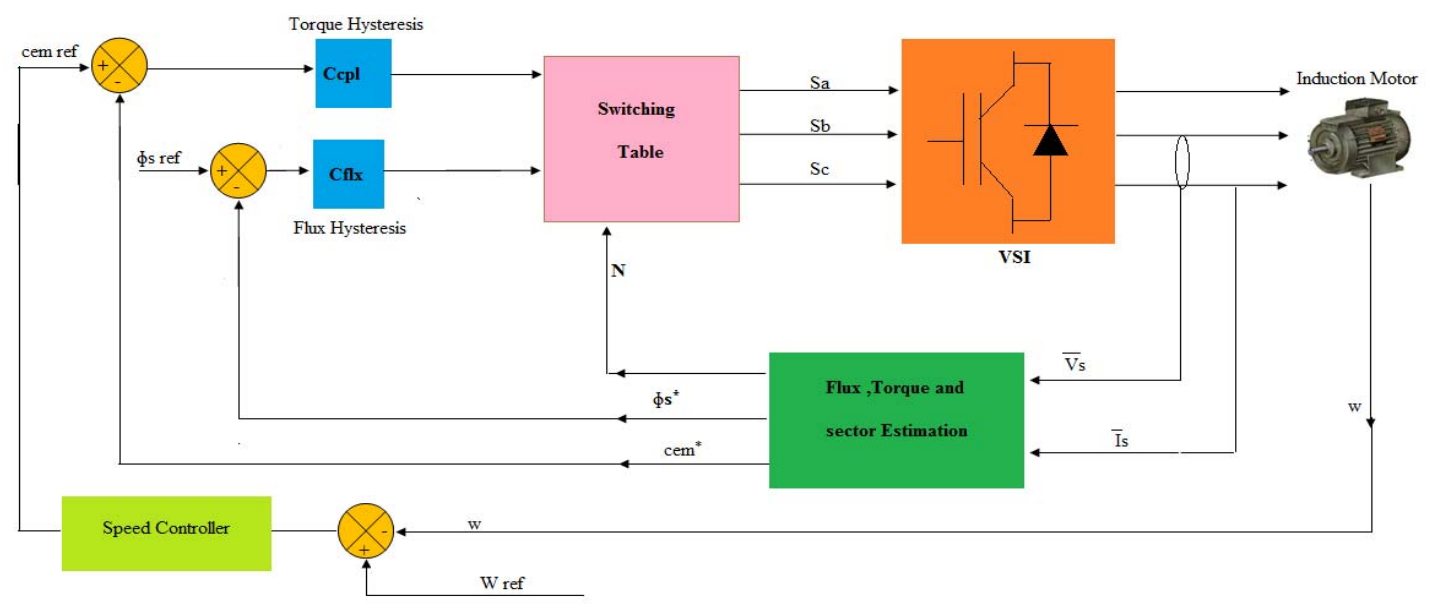

Figure 1. Structure ofclassical DTC.

This strategy is based generally on the use of hysteresis comparators whose role is to control the amplitudes of the stator flux and the electromagnetic torque: [8].

$$
\begin{aligned}
& \left\{\begin{array}{l}
\Phi_{s \alpha}=\int_{0}^{t}\left(v_{s \alpha}-R_{s} i_{s \alpha}\right) d t \\
\Phi_{s \beta}=\int_{0}^{t}\left(v_{s \beta}-R_{s} i_{s \beta}\right) d t
\end{array}\right. \\
& T_{e}=\frac{3}{2} p\left[\begin{array}{c}
\Phi_{s} \alpha i_{s} \beta^{-} \\
\Phi_{s} \beta i_{s} \alpha
\end{array}\right]
\end{aligned}
$$

Int J Pow Elec \& Dri Syst, Vol. 10, No. 2, June 2019：697 - 708 
The DTC control method allows direct and independent electromagnetic torque and flux control, selecting an optimal switching vector, the Figure 2 shows the schematic of the basic functional blocks used to implement the DTC of induction motor drive. A voltage source inverter (VSI) supplies the motor and it is possible to control directly the stator flux and the electromagnetic torque by the selection of optimum inverter switching modes [9].

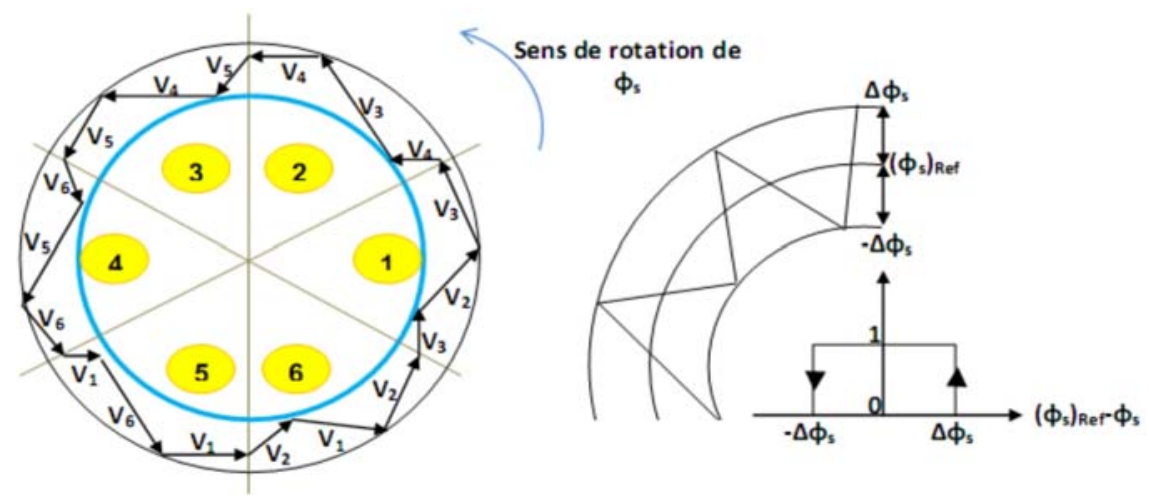

Figure 2. Voltage vectors.

The switching table allows to select the appropriate inverter switching state according to the state of hysteresis comparators of flux (cflx)and torque (ccpl)and the sector where is the stator vector flux $\left(\varphi_{\mathrm{s}}\right)$ in the plan $(\alpha, \beta)$, in order to maintain the magnitude of stator flux and electromagnetic torque inside the hysteresis bands. The above consideration allows construction of the switching table [10], is given in Table 1.

Table 1. The selection of electrical tention

\begin{tabular}{|c|c|c|c|c|c|c|c|}
\hline \multicolumn{2}{|c|}{$\mathrm{N}$} & \multirow[t]{2}{*}{1} & \multirow[t]{2}{*}{2} & \multirow[t]{2}{*}{3} & \multirow[t]{2}{*}{4} & \multirow[t]{2}{*}{5} & \multirow[t]{2}{*}{6} \\
\hline Cflx & Ccpl & & & & & & \\
\hline \multirow[t]{3}{*}{1} & 1 & 2 & 3 & 4 & 5 & 6 & 1 \\
\hline & 0 & 7 & 0 & 7 & 0 & 7 & 0 \\
\hline & -1 & 6 & 1 & 2 & 3 & 4 & 5 \\
\hline \multirow[t]{3}{*}{ 0 } & 1 & 3 & 4 & 5 & 6 & 1 & 2 \\
\hline & 0 & 0 & 7 & 0 & 7 & 0 & 7 \\
\hline & -1 & 5 & 6 & 1 & 2 & 3 & 4 \\
\hline
\end{tabular}

\section{DTC WITH INTELLIGENCE ARTIFICIAL NEURONAL (DTC-ANN)}

Conventional DTC control has several disadvantages, such as obtaining a variable switching frequency, torque and flux ripples, power fluctuations, and harmonic currents in the transient and steady state, because of the use of hysteresis comparators and switching tables. For this, we proposed to study in this part the direct control of the pair based on artificial neural networks, to improve the performance of the DTC commands, where the conventional comparators and the switching table are replaced by a neural controller, so to drive the output quantities of the MAS to their reference values for a fixed period of time. Numerical simulations are presented to test the performances of the proposed methods (DTC-ANN) [11].

The structure of the direct neural control of the torque (DTC-ANN-2N), of the asynchronous machine powered by two-level NPC inverter, is represented by Figure 3. 


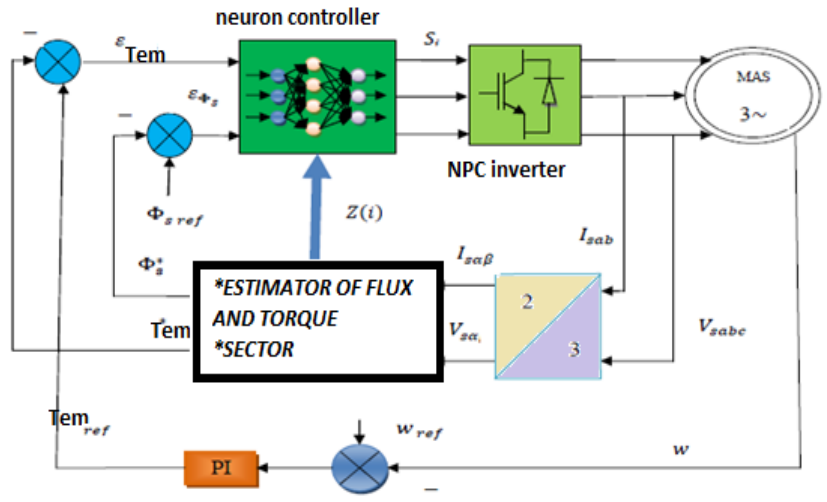

Figure 3. DTC-ANN (DTC by Artificial Neural Network)

The update of the weights and Bias of this network is carried out by a retro-propagation algorithm called the Levenberg-Marquardt (LM) algorithm.

The choice of neural network architecture is based on the mean squared error (MSE) obtained during learning [12]. The following figure shows the structure of neural networks for two-level neuronal Design of KUBOTA observer.

\section{THE OBSERVATION}

The estimators used in open loop, based on the use of a copy of a model representation of the machine.This approach led to the implementation of simple and fast algorithms, but sensitive to modeling errors and parameter variations during operation [13].

Is an estimator operating in a closed loop and having an independent system dynamics. It estimates an internal physical quantity of a given system, based only on information about the inputs and outputs of the physical system with the feedback input of the error between estimated outputs and actual outputs, using the $\mathrm{K}$ matrix gain to thereby adjust the dynamic convergence error [4].

The structure of the adaptive observer of KUBOTA (or MRAS) is illustrated in Figure 4 when the rotational speed of the machine is not measured, it is considered as an unknown parameter in the observer's system of equations based on the state model. This state model is given below [15].

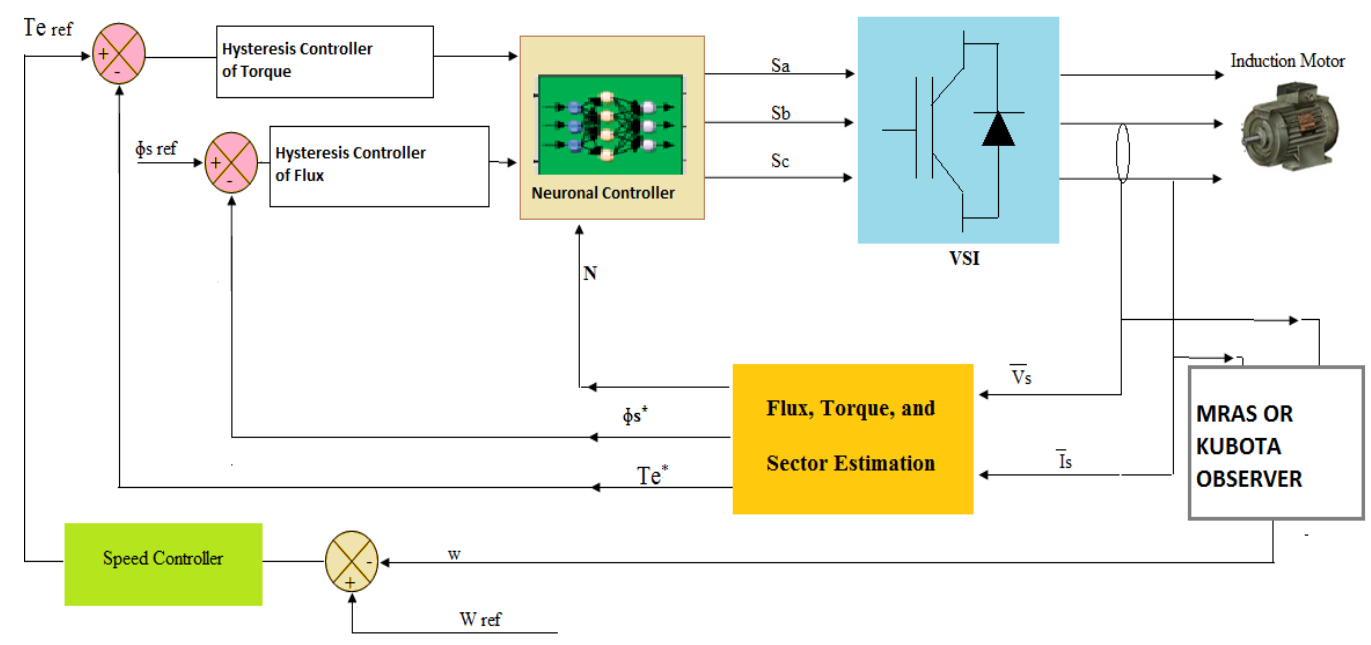

Figure 4. DTC-ANN associated with the KUBOTA observer 


\subsection{Representation of the KUBOTA observer}

The structure of the KUBOTA Adaptive Observer is illustrated in Figure 5. [16], [17], [18]. When the rotation speed of the MAS is not measured, it is considered as an unknown parameter in the observer equation system based on the vector state model of the induction machine described in the stator frame and having as state vector.

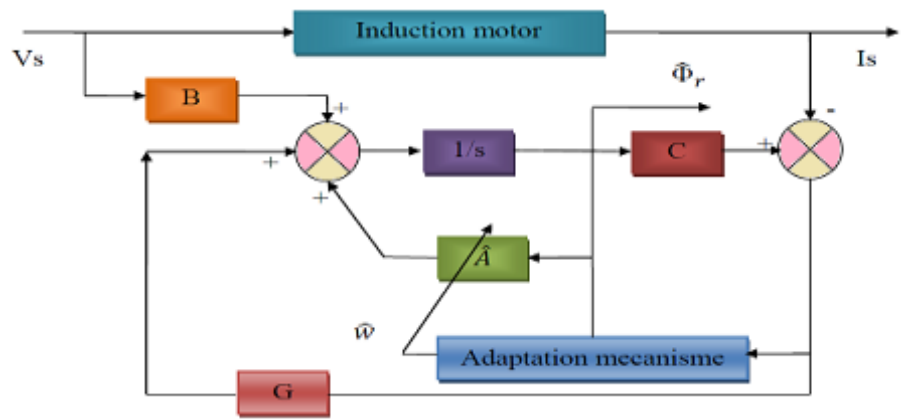

Figure 5. The Observer of KUBOTA

4.2. The modelling of the observer of KUBOTA

4.2.1.State model

$$
\left\{\begin{array}{l}
x=A x+B u \\
y=C x
\end{array}\right.
$$

With:

$$
[A]=\left[\begin{array}{ll}
A 11 & A 12 \\
A 21 & A 22
\end{array}\right] \quad x=\left[\begin{array}{l}
I S \\
\varphi_{r}
\end{array}\right]
$$

So the observatory associated with this model is written as:

$$
\frac{\tilde{a}}{d t}=\tilde{A} \tilde{x}+B_{u S}+G\left(I_{s}-\tilde{I}_{s}\right)
$$

with:

$$
G=\left|\begin{array}{cccc}
g_{1} & g_{2} & g_{3} & g_{4} \\
-g_{2} & g_{1} & -g_{4} & g_{3}
\end{array}\right|^{T}
$$

By asking thate $=\chi-\tilde{\chi}$ estimation error between the model and the observer.

$$
\frac{d e}{d t}=(A-G C) e-\Delta-\tilde{x}
$$

\subsubsection{Adaptation mechanism}

The speed adjustment mechanism is derived from the application of Lyapunov theorem on system stability. Let Lyapunov function defined positive [16]:

DTC hybrid by different techniques of observation with ANN (Artificial Neuronal Network)... (Dris Ahmed) 


$$
V=e^{T} e+\frac{(w-\tilde{w})^{2}}{\lambda}
$$

Otherwise, the derivative of this function with respect to time is negative:

$$
\frac{d V}{d t}=e^{T} Q_{e}-2 \Delta w\left[k \left(_{e i s} \alpha \widetilde{\varphi}_{r} \beta^{-} \text {eis } \beta \widetilde{\varphi}_{r} \alpha^{\left.\left.-\frac{d \tilde{w}}{\lambda d t}\right)\right]}\right.\right.
$$

with:

$$
\begin{aligned}
& \text { eis } \alpha={ }_{i s \alpha} \tilde{i}_{s} \alpha \cdot \operatorname{cis} \beta={ }_{i s \beta}-\tilde{i}_{s \beta} \\
& Q=(A-G C)^{T}+(A-G C)
\end{aligned}
$$

The (8) must be set negative according to the Lyapunov stability theory. Therefore, by careful selection of the gain matrix G, the matrix Q must be a negative definite matrix and the adaptation mechanism for estimating the speed will be reduced by cancellation of the $2^{\text {nd }}$ term of the (9)[17].

The estimate of the speed is done by the following law:

$$
\widetilde{\omega}=k \lambda \cdot j\left(e_{i s} \alpha \tilde{\varphi}_{r \beta}-e^{i s \beta} \tilde{\varphi}_{r} \alpha\right) d t
$$

To improve the speed of dynamic observation, propose to use PI instead of a pure integrator:

$$
\tilde{\omega}=k_{p} \cdot\left(e_{i s} \alpha \tilde{\varphi}_{r \cdot \beta^{-}} e_{i s} \beta \tilde{\varphi}_{r} \alpha\right){ }_{k i}\left\lceil\left(e_{i s} \alpha \tilde{\varphi}_{r} \beta^{-} e_{i s} \beta \tilde{\varphi}_{r} \alpha\right) d t\right.
$$

\subsection{Adaptation system with reference model}

This technique is designed on the basis of an adaptive system using two estimators flux, the first not introducing speed is called the reference model (or voltage model). The second, which is a function of speed is called adjustable model (or current model), the error produced by offset between the outputs of the two pilot estimators an adaptation algorithm that generates the estimated speed [18], as shown in Figure 6.

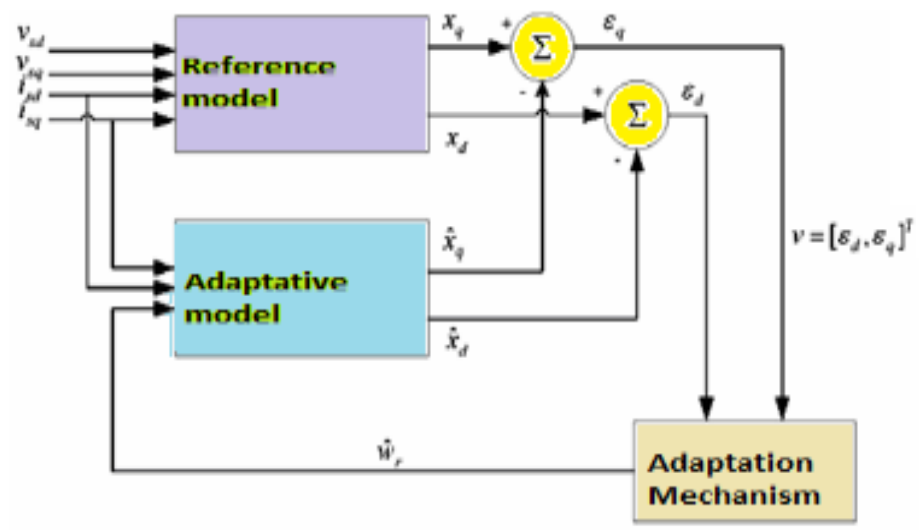

Figure 6. The structure of the MRAS technique 
The basic model

From stator and rotor equations of the asynchronous machine, we have:

Reference model

$$
\left\{\begin{array}{l}
\frac{d \varphi_{r} \alpha}{d t}=\frac{L_{r}}{M}\left(V_{s} \alpha-R_{s} \cdot I_{s} \alpha-\sigma_{L_{s}} \cdot \frac{d I_{s} \alpha}{d t}\right) \\
\frac{d \varphi_{r \beta}}{d t}=\frac{L_{r}}{M}\left(V_{s \beta}-R_{s} \cdot I s \beta-\sigma_{L s} \cdot \frac{d I_{s \beta}}{d t}\right)
\end{array}\right.
$$

Adjustable model

$$
\left\{\begin{array}{l}
\frac{d \tilde{\varphi}_{r \alpha}}{d t}=-\frac{1}{T_{r}} \tilde{\phi}_{r \alpha}-P \Omega_{\tilde{\phi}_{r \alpha}}+\frac{M}{T_{r}} I_{s \alpha} \\
\frac{d \tilde{\phi}_{r \beta}}{d t}=-\frac{1}{T_{r}} \tilde{\varphi}_{r \beta}+P \tilde{\Omega}+\frac{M}{T_{r}} I s \beta
\end{array}\right.
$$

The algorithm of adaptation is chosen so as to converge the adjustable model to the reference model to minimize the error andhave the stability of the model. For this, the algorithm parameters are defined according to the criterion ofhyper stability saidPopov.

The error between the states of the two models can be expressed in matrix form by:

$$
\left[\begin{array}{ll}
\varepsilon & \alpha \\
\varepsilon & \beta
\end{array}\right]=\left[\begin{array}{l}
0+\alpha-\tilde{\theta}+\alpha \\
0+\beta-\tilde{\theta}+\beta
\end{array}\right]
$$

with:

$$
\frac{d}{d t}\left[\begin{array}{l}
\varepsilon \alpha \\
\varepsilon \beta
\end{array}\right]=\left[\begin{array}{cc}
-\frac{1}{T_{r}} & -\omega \\
\omega & -\frac{1}{T_{r}}
\end{array}\right] \cdot\left[\begin{array}{l}
\varepsilon \alpha \\
\varepsilon \beta
\end{array}\right]-\left[\begin{array}{c}
\sigma_{r \alpha} \\
\sigma_{r \beta}
\end{array}\right] \cdot(\omega-\tilde{\omega})
$$

and:

$$
\frac{d}{d t}[\varepsilon]=[A] \cdot[\varepsilon]-[W]
$$

Schauder offers an adaptationlawthatmeetsthe criterion of Popov and given by the equation:

$$
\tilde{\omega}=Q_{2}(\varepsilon)+\int_{0}^{t} Q_{1}(\varepsilon) d r
$$

the criterion of Popov requires satisfaction of the following integral:

$$
\int_{0}^{t} \varepsilon^{T} \cdot \pi d t \geq-\gamma^{2}, \gamma>0
$$

using (15), while replacing $\varepsilon$ and w by their values, we obtain:

$$
\int_{0}^{t}\left\{\left[\varepsilon \alpha \cdot \partial_{r \beta}-\varepsilon \beta \cdot \partial_{r \alpha}\right] \cdot\left[\omega-\underline{Q}_{2}(\varepsilon)-j_{0}^{t} Q_{1}(\varepsilon) d t\right]\right\} d t \geq-\gamma^{2}
$$

the solution of (16) can be found using the following relation:

DTC hybrid by different techniques of observation with ANN (Artificial Neuronal Network)... (Dris Ahmed) 


$$
\int_{0}^{t} k \cdot\left(\frac{d f(t)}{d t}\right) f(t) d t \geq-\frac{1}{2} k f(0)^{2}, k \geq 0
$$

using the latter equation for solving Popov of the integral, the following functions are obtained:

$$
\left\{\begin{array}{l}
Q_{1}=k_{i}\left(\varphi_{r \beta} \tilde{\varphi}_{r \alpha}-\varphi_{r \alpha} \cdot \tilde{\varphi}_{r \beta}\right) \\
Q_{2}=k_{p}\left(\varphi_{r \beta} \cdot \tilde{\varphi}_{r \alpha}-\varphi_{r \alpha} \cdot \tilde{\varphi}_{r \beta}\right)
\end{array}\right.
$$

by replacing this system of (17) yields the value estimated by the following adaptation law:

$$
\tilde{\omega}=k_{p}\left(\varphi_{r \beta} \tilde{\varphi}_{r \alpha}-\varphi_{r \alpha} \tilde{\varphi}_{r \beta}\right)+k \int_{0}^{t}\left(\varphi_{r \beta} \tilde{\varphi}_{r \alpha}{ }^{-\varphi_{r \alpha}} \tilde{\varphi}_{r \beta}\right)
$$

\section{SIMULATION RESULTS}

The direct torque control applied to an induction machine is simulated under the Matlab/Simulink environment. The simulation is performed under the same conditions, Result shown in Figures (7 to 16) to estimate the speed, estimate the flux, test of the low speed.
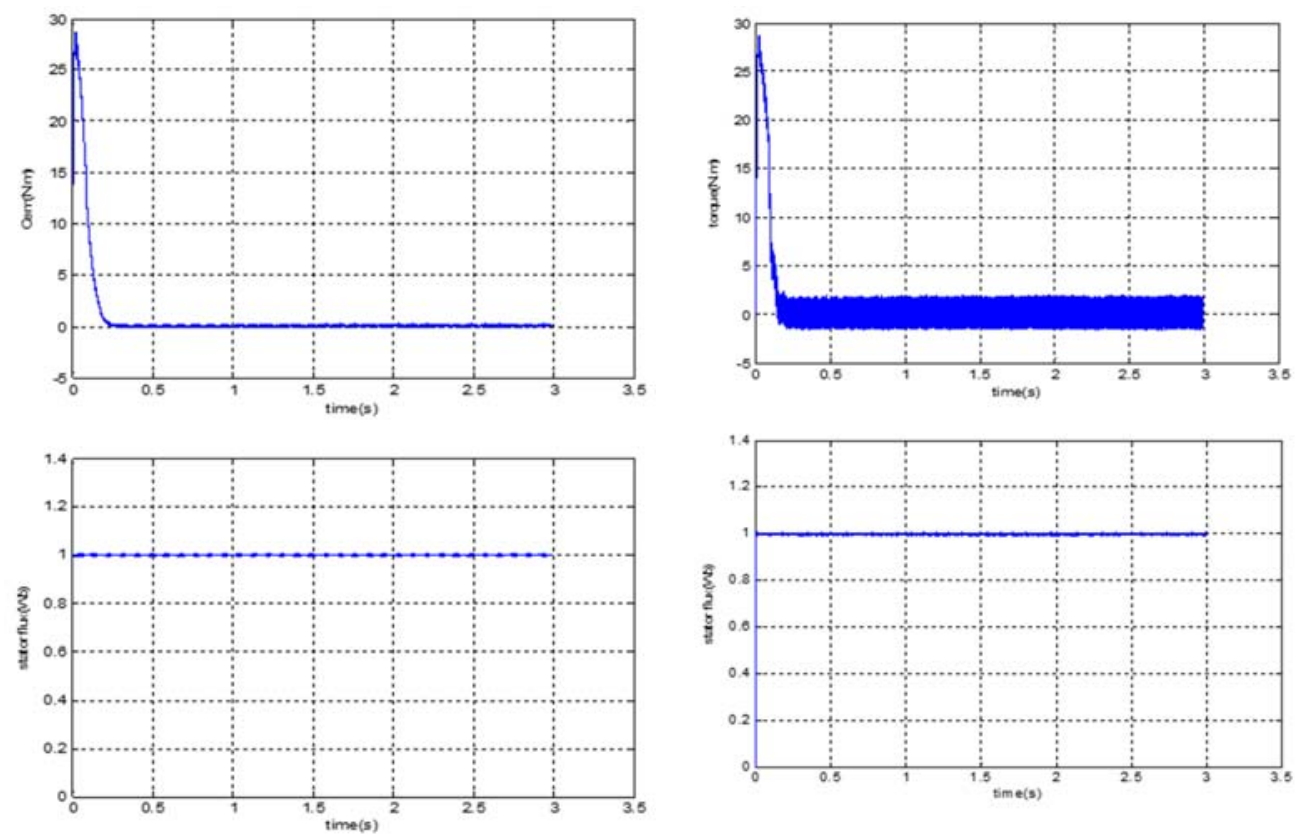

Figure 7. DTC-ANN

Figure 8. Classical DTC 

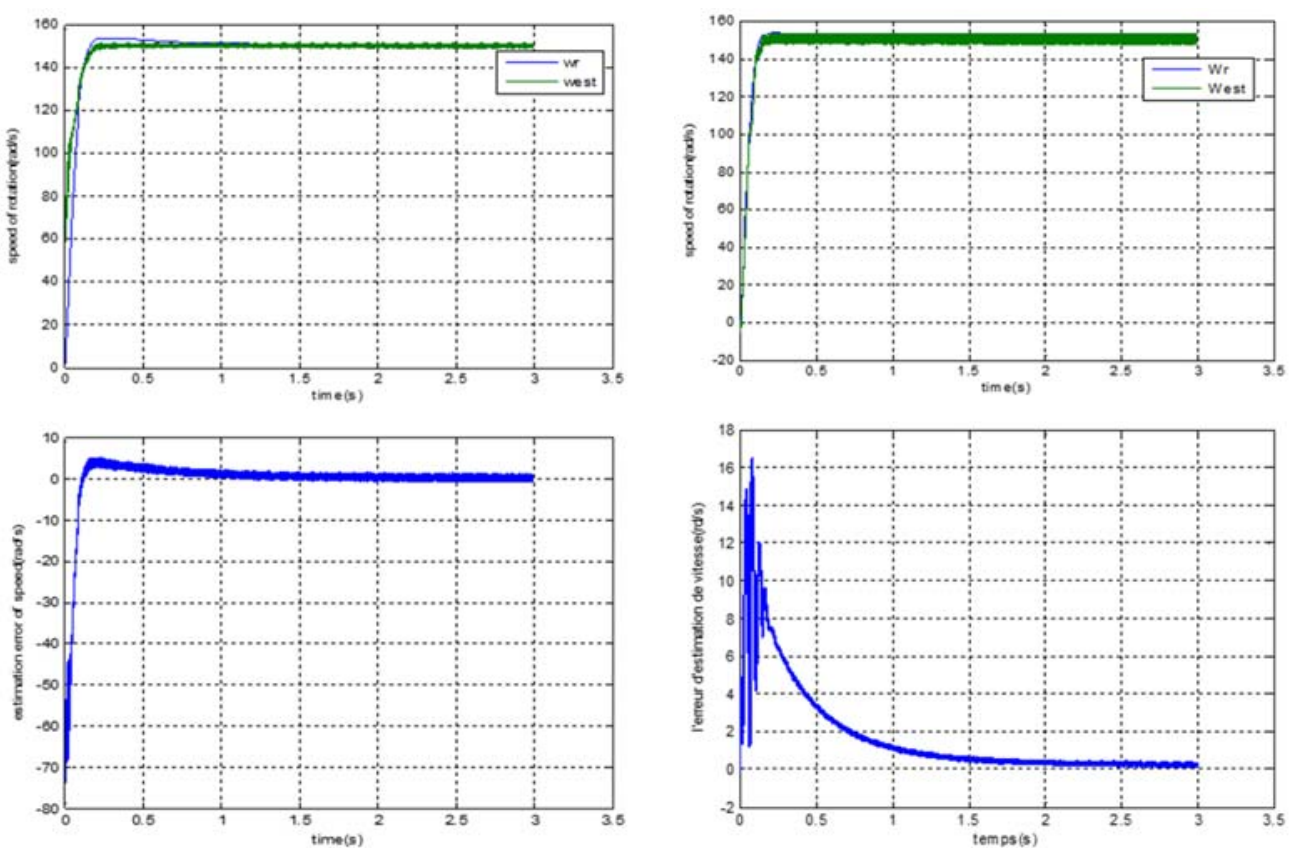

Figure 9. DTC-ANN with MRAS

Figure 10. DTC-ANN with KUBOTA
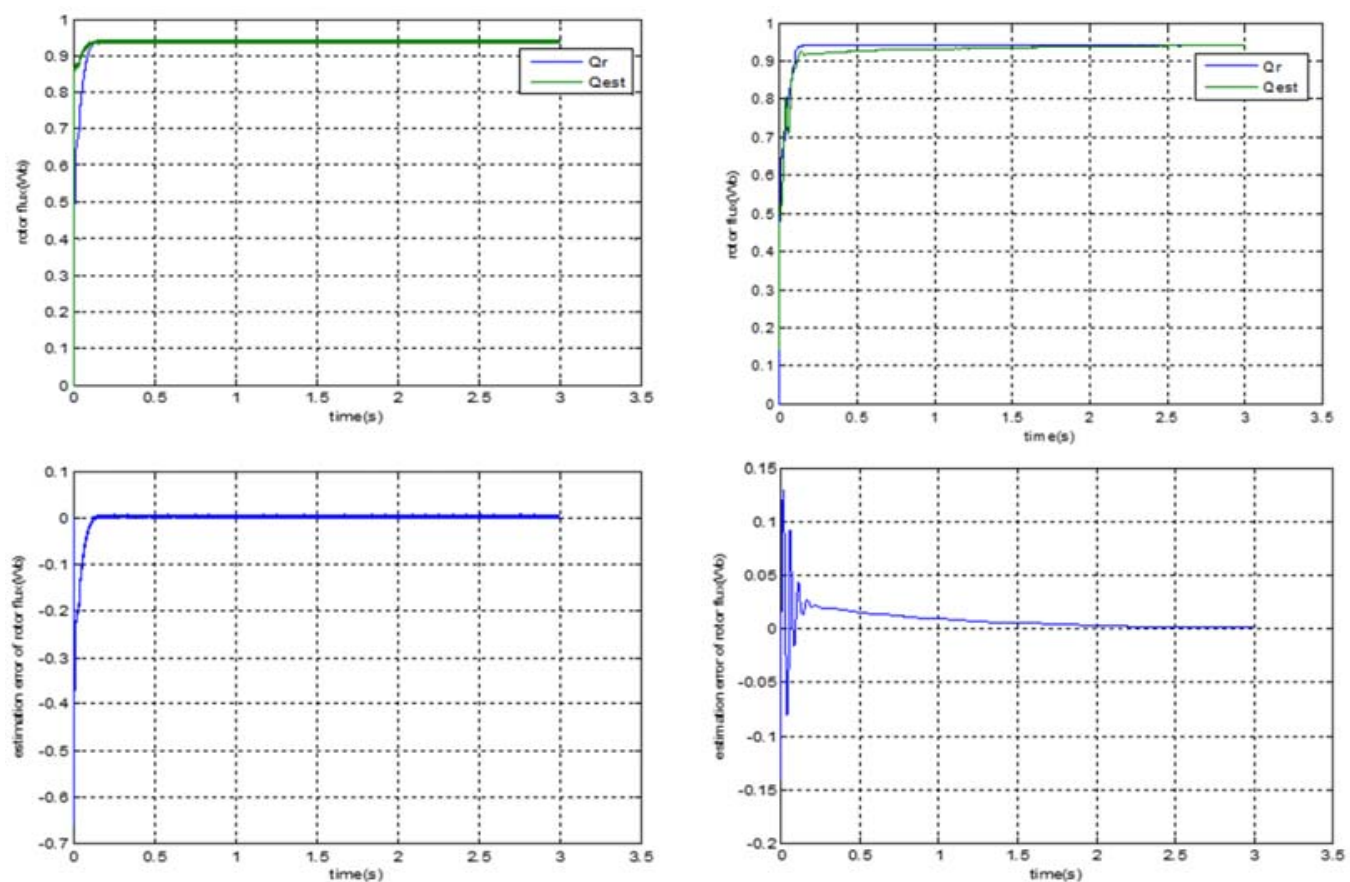

Figure 11. DTC-ANN control with MRAS

Figure 12. DTC-ANN control with KUBOTA 


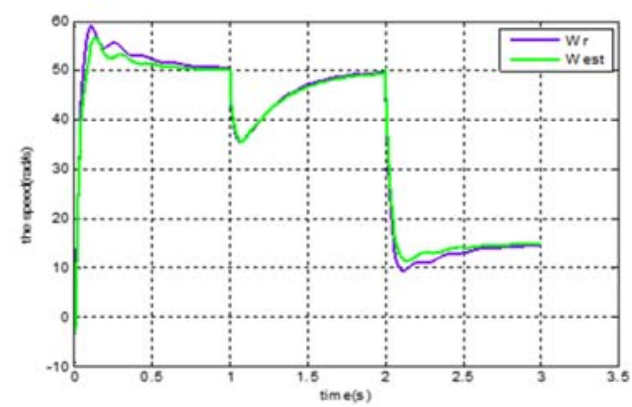

Figure 13. DTC-ANN control with MRAS
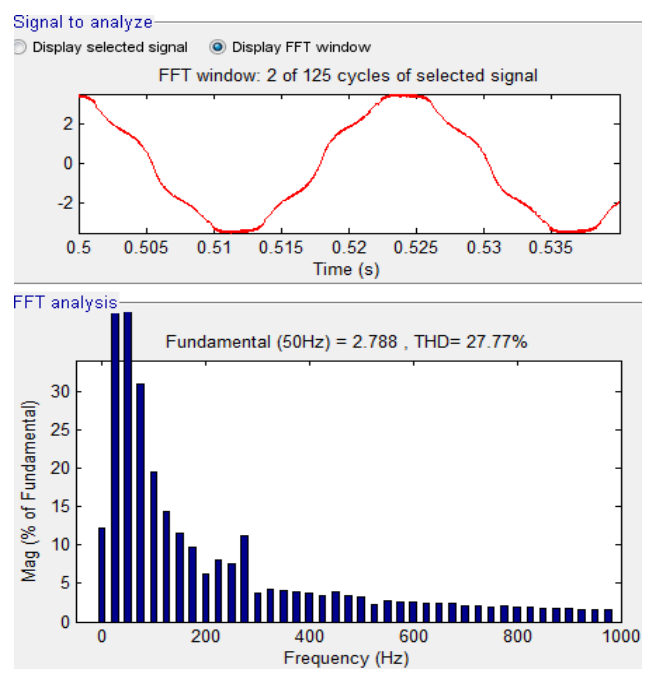

Figure 15. THD value of classical DTC

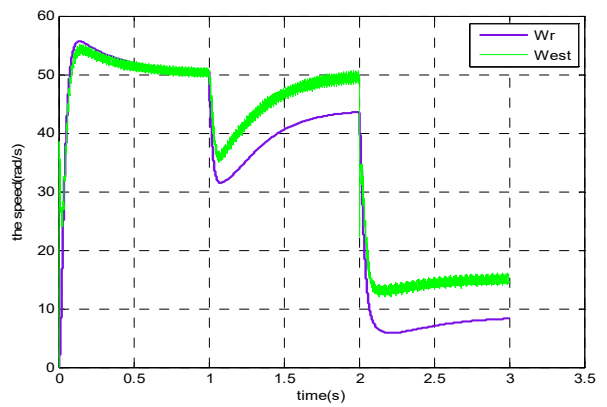

Figure 14. DTC-ANN control with KUBOTA
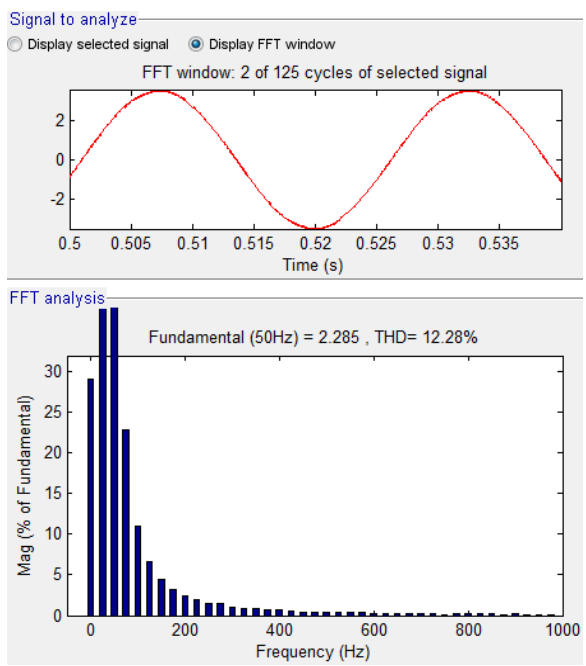

Figure 16. THD value of DTC-ANN

These results prove that our sensorless control with adaptation of is insensitive to the variations of the stator resistances. It is also noticed that the observer corrects well the rotor flux (the square of the rotor flux) and the speed of rotation, since the estimated quantities follow 'an acceptable way the actual magnitudes of the machine, hence a tracking error is almost zero between the two sizes. This implies a stable observation. But we have a problem of the ripples, especially for the observer of KUBOTA, we can say that the MRAS estimator is robust by bringing the observer of KUBOTA in this case. Detail is shown in Table 2.

Table 2. Comparison between the performances of MRAS and KUBOTA observer

\begin{tabular}{ccccc}
\hline & Precision & swiftness & Oscillation & Low speed \\
\hline MRAS & Accurate & Fast & Existing & Good \\
KUBOTA & More accurate & Fast below & Missing & Excellent \\
& & & & $\approx 10 \mathrm{Rad} / \mathrm{s}$ \\
\hline
\end{tabular}

Simulation results show that using the observer is important in the control of the machine, the estimation erroras zero in the steady state, The major advantage for KUBOTA observation technique it's insensitivity to the machine settings. Computer simulation results obtained confirm the validity and effectiveness of the proposed control approach at low speed compared to results of the paper in [5].

Comparison of all the above performance parameters of the drive with KOBOTA as well as adaptive controller for MRAS proves the effectiveness of MRAS with Neuro Fuzzy adaptive controller as speed estimator for the low speed estimation issues in sensorless DTC IM drives paper of the [6], Figure 15 and Figure 16 shows THD of the stator current.

Int J Pow Elec \& Dri Syst, Vol. 10, No. 2, June 2019: 697 - 708 
Table 3 shows that the simulation results using artificial intelligence techniques (neural hysteresis) show that the tracking of the set point is perfect. We note that the ripple of electromagnetic torque and stator flux reduces perfectly compared to conventional DTC without neural hysteresis comparator It is more apparent through the trajectory of the stator flux In addition to a large decrease in THD as shown in the table above, We were able to conclude that the DTC control by neural hysteresis showed good performance than the classical DTC control.

Table3. Comparison between the performances of DTC classical and DTC-ANN
\begin{tabular}{cccc} 
& $\begin{array}{c}\text { Minimizations ripples } \\
\text { of the torque }\end{array}$ & $\begin{array}{c}\text { Minimizations } \\
\text { ripples of the flux }\end{array}$ & $\begin{array}{c}\text { Ias } \\
\text { THD (\%) }\end{array}$ \\
\hline DTC classic & Exist & Exist & 27.77 \\
DTC - ANN & Few & Few & 12.28 \\
\hline
\end{tabular}

\section{CONCLUSIONS}

In this paper, we mainly presented the estimation of the rotor flux by the KUBOTA adaptive state observer, then we evaluated the estimation error of the flux, we also devoted to improve the performances of the direct control of the torque of the asynchronous two-level UPS powered machine based on artificial intelligence techniques by DTC-ANN, The simulation results show that the use of both estimators is important in the control of the induction machine, the transient and very short regime and the error between the flux estimated and measured to zero in the steady state, the robustness tests of the estimator are also verified. According to the simulation results too, we notice that the estimation by MRAS technique performance (a little overflow, short response time, no oscillations, robust), but the observer KUBOTA also play its role, and give good result and almost similar by contribution to the 1st observer The major disadvantage of the speed estimation based on MRAS is its high sensitivity to the parameters of the machine For this, several works have proposed online adaptation techniques the stator resistance and also rotor resistance. Finally we can say the use of the estimator brings a clear improvement to the looped structure.Note that the research work is very few, especially with regard to the observer of KUBOTA so I want to expand further and using different controls.

\section{REFERENCES}

[1] X.F. Morand, "Technique d'observation sans capteurs de vitesse en vue de la commande desmachinessynchrone,"Thèse de doctorat, institue national des sciences appliquées, Lyon France 2005.

[2] A. Ameur, "Commande sans capteur de vitesse par DTC d'une machine synchrone à aimants doté d'un observateur d'ordre complet à SMC,",Thèse de magister en électrotechnique, université Batna, 2003.

[3] I. Al-Rouh, "Contribution à la commande sanscapteur de la MAS,"Thèse de doctorat, Univ Henri Poincaré, Nancy -1, Juillet 2004.

[4] D. Abdelghani, A. Boumediène, "Direct Torque Control of Two Induction Motors Using the Nine-Switch Inverter," International Journal of Power Electronics and Drive System (IJPEDS), vol. 9(4), pp. 1552-1564, Dec 2018.

[5] Djamila Cherifi, Yahia Miloud, "Robust Speed-Sensorless Vector Control of Doubly Fed Induction Motor Drive Using Sliding Mode Rotor Flux Observer," International Journal of Applied Power Engineering (IJAPE),vol.7(3), pp. 248-263, , Dec 2018.

[6] Mini R., S. Backer, B. Satheesh, M. Dinesh, "Low Speed Estimation of Sensorless DTC Induction Motor Drive Using MRAS with Neuro Fuzzy Adaptive Controller," International Journal of Electrical and Computer Engineering (IJECE), vol. 8(5), pp. 2691-2702, Oct 2018.

[7] V. Bostan, M. Cuibus, C. Ilas, G. Griva, F. Profumo, R. Bojoi, "General adaptation law for MRAS high performance sensorless induction motor drives," PESC, Vancouver, Canada, vol 17(22), June.

[8] H. Kubota, K. Matsuse, T. Nakano "DSP-based speed adaptive flux observer of induction motor," IEEE Transactions on Industry.

[9] B. Sebti, "Commande par DTC d'un moteur asynchrone apport des réseaux de neurones,"Mémoire de Magister, université de Batna, 2013.

[10] D. Yacine, "Contrôle de la fréquence de commutation des hystérésis utilisés dans les commandes d'une machine à induction," Mémoire de Magister, université de Batna, 2007.

[11] B. Elakhdar, "Commande directe du couple floue et neuronale d'un moteur synchrone à double étoile sans capteur mécanique alimenté par onduleurs Multiniveaux," Thèse doctorat en sciences, université Djillali Liabes-Sidi Bel Abbés, 2015.

[12] M. Birame, B. Mokhtari, L. Mokrani, B. Azoui, A. Naamane, N. M'sirdi, "Co-mpensateur PI flou de la variation de la résistance statorique d'un moteur à reluctance variable commande par DTC," Article, Publisher JEE, vol 53(4), 2012. 
[13] D. Yousef, "Commande directe du couple et des puissances d'une MADA associée à un systéme éolien par les techniques de l'intelligence artificielle," These Doctroat en science,université Djillali liabes de SidiBel-Abbes, 2015

[14] A. Hammoumi, A. Massoum, A. Meroufel, P. Wira, "Application des Réseaux de Neurones pour la commande de la machine Asynchrone sans capteur mécanique," Article ,Medimira science Publisher, vol. 53(2), 2012.

[15] L. Youb, A. Cracunescu, "Etude Comparative entre la commande vectorielle a flux oriente et la commande directe du couple de la machine asynchrone," U.P.B.SCI.Bull,series C, vol.69(2), 2007.

[16] Kubota, H., Matsuse, K., "Speed sensorless field oriented control of induction motor with Rotor resistance adaptation," Proceeding of IEEE-IAS 1993 Annual Meeting, vol. 1, pp. 414 - 418, Toronto, Canada, Oct. 1993.

[17] D. Ahmed ,B. Mokhtar, B. Habib, "Two-level DTC control based on neural hysteresis comparators with sensorless induction machine drives using kubota observer," (JARST), vol 5(1), 2018.

[18] D. Ahmed, "Etude des différentes stratégies de commande non linéaire de la machine asynchrone avec estimation du flux et de la vitess," Mémoire de Magister, Ecole Nationale Polytechnique d'Oran, 2015.

Int J Pow Elec \& Dri Syst, Vol. 10, No. 2, June 2019 : 697 - 708 